This is an electronic reprint of the original article. This reprint may differ from the original in pagination and typographic detail.

Author(s): Kumar, Hemanathan; Alén, Raimo

Title: $\quad$ Microwave-assisted Esterification of Tall Oil Fatty Acids with Methanol Using Ligninbased Solid Catalyst

Year: $\quad 2016$

Version:

Please cite the original version:

Kumar, H., \& Alén, R. (2016). Microwave-assisted Esterification of Tall Oil Fatty Acids with Methanol Using Lignin-based Solid Catalyst. Energy and Fuels, 30(11), 94519455. https://doi.org/10.1021/acs.energyfuels.6b01718

All material supplied via JYX is protected by copyright and other intellectual property rights, and duplication or sale of all or part of any of the repository collections is not permitted, except that material may be duplicated by you for your research use or educational purposes in electronic or print form. You must obtain permission for any other use. Electronic or print copies may not be offered, whether for sale or otherwise to anyone who is not an authorised user. 


\section{Article}

\section{Microwave-assisted Esterification of Tall Oil Fatty Acids with Methanol Using Lignin-based Solid Catalyst}

Hemanathan Kumar, and Raimo Alén

Energy Fuels, Just Accepted Manuscript • DOI: 10.1021/acs.energyfuels.6b01718 • Publication Date (Web): 05 Oct 2016

Downloaded from http://pubs.acs.org on October 12, 2016

\section{Just Accepted}

"Just Accepted" manuscripts have been peer-reviewed and accepted for publication. They are posted online prior to technical editing, formatting for publication and author proofing. The American Chemical Society provides "Just Accepted" as a free service to the research community to expedite the dissemination of scientific material as soon as possible after acceptance. "Just Accepted" manuscripts appear in full in PDF format accompanied by an HTML abstract. "Just Accepted" manuscripts have been fully peer reviewed, but should not be considered the official version of record. They are accessible to all readers and citable by the Digital Object Identifier (DOI®). "Just Accepted" is an optional service offered to authors. Therefore, the "Just Accepted" Web site may not include all articles that will be published in the journal. After a manuscript is technically edited and formatted, it will be removed from the "Just Accepted" Web site and published as an ASAP article. Note that technical editing may introduce minor changes to the manuscript text and/or graphics which could affect content, and all legal disclaimers and ethical guidelines that apply to the journal pertain. ACS cannot be held responsible for errors or consequences arising from the use of information contained in these "Just Accepted" manuscripts. 


\title{
Microwave-assisted Esterification of Tall Oil Fatty Acids with Methanol Using Lignin-based Solid Catalyst
}

\author{
Hemanathan Kumar* and Raimo Alén \\ Laboratory of Applied Chemistry, University of Jyväskylä \\ P.O. Box 35, Jyväskylä FI-40014, Finland \\ *Corresponding author \\ Email: hemanathan.k.kumar@jyu.fi \\ Tel: +358-44-9641943
}

30

32

33

34

35

36

37

38

39

40

41

42

43

44

45

46

47

48

49

50

51

52

53

54

55

56

57

58

59

60 


\begin{abstract}
During alkaline pulping significant amounts of lignin, carbohydrates (mostly hemicelluloses), and extractives (tall oil soap and turpentine) are removed from wood feedstock. In this study, the catalytic esterification of fatty acids in tall oil with methanol to produce fatty acid methyl esters under microwave irradiation was performed at $100{ }^{\circ} \mathrm{C}$ for $10-60 \mathrm{~min}$. A novel heterogeneous acid catalyst tested for this purpose was synthesized from the hardwood alkali lignin that was precipitated by acidification from the black liquor from soda-AQ pulping. The comparative reaction data were obtained by using other solid catalysts, Amberlyst 15 and $p$ toluenesulfonic acid. The results showed the highest esterification yields 93,88 , and $80 \%$ with the $p$-toluenesulfonic acid, lignin-based, and Amberlyst 15 catalysts, respectively, at 100 ${ }^{\circ} \mathrm{C}$ with a reaction time of $60 \mathrm{~min}$ and the corresponding yield without catalyst was $20 \%$. It was also observed that the lignin-based catalyst could be easily recovered and reused without any notable deactivation.
\end{abstract}




\section{Introduction}

Biofuels have recently gained significant attention because of their environmental benefits and gradually increasing scarcity in fossil fuels. ${ }^{1-3}$ They are non-toxic, renewable, and biodegradable fuels that traditionally consist of fatty acid (m)ethyl esters (FAMEs or FAEEs). ${ }^{4,5}$ The benefits towards their use also include sustainability, reduction of greenhouse gas emissions, ${ }^{3}$ and can be directly used in the existing engines without any practical modifications. ${ }^{1,6}$ However, raw material and production costs form the major limitation on the growth of industrial-scale biofuel production. ${ }^{7,8}$ For this reason, clearly more research to exploring novel ways towards the sustainable and economically feasible production methods is still needed. Especially, the further development of stable, heterogeneous, and recyclable catalysts, being based on low-cost and wide-scale available feedstocks and, on the other hand, on their effective production methods with minimal energy consumption would be of benefit.

The extractives such as non-volatile crude tall oil (CTO) soap and volatile crude turpentine, as well as the cooking liquor ("black liquor", BL) that contains mostly lignin and carbohydrate-derived aliphatic carboxylic acids, comprise the by-products obtained from alkaline pulping. ${ }^{9}$ Carboxylic acids (i.e., fatty and resin acids) in the CTO soap are liberated by adding sulfuric acid and the CTO formed is purified and fractionated by vacuum distillation to obtain various commercial products including tall oil fatty acids (TOFAs) and tall oil rosin (TOR) together with light oil, distilled tall oil (DTO), and tall oil pitch. ${ }^{9-12}$ In contrast, $\mathrm{BL}$ is evaporated and burned in a recovery furnace to generate energy and recover the inorganic cooking chemicals. In spite of the modern delignification and recovery processes, alkaline pulping is facing major challenges and will need to find new products with a moderate added value in order to remain competitive.

Extensive research has been devoted to produce biodiesel from the CTOderived fatty acids; ${ }^{5,13,14}$ for example, a wide range of investigations has been conducted on the utilization of homogeneous and heterogeneous acid catalysts for esterifying fatty acids. The major drawback of the use of soluble homogeneous catalysts lies in their reusability and, on the other hand, in the purification of products. ${ }^{15,16}$ Therefore, in recent years, much attention has also been paid to the use of recyclable solid catalysts, although they may be easier to deactivate over time, leading to a loss of both productivity and reaction selectivity compared to the use of homogeneous catalysts. Normally, relatively expensive carbohydratebased biomass has been used as raw material for producing solid acid catalysts. ${ }^{15,17-19}$ In 
contrast, economically a more attractive approach would be to use by-product alkali lignin for this purpose. However, at present only limited literature data are available on the production of lignin-based solid catalysts and their applications. ${ }^{20,21}$

The main aims of this study (Figure S1) were i) to prepare and characterize a solid acid catalyst from alkaline lignin by the phenol formaldehyde condensation reaction followed by the sulfonation reaction and ii) to produce FAMEs from TOFAs and methanol under microwave irradiation by means of this lignin-based catalyst.

\section{Materials and methods}

\subsubsection{Catalyst preparation}

The lignin-based acid catalyst was prepared from the precipitated hardwood (birch, Betula Pendula) lignin obtained by acidification ( $\mathrm{pH}$ to about 2) of hardwood sodaAQ BL. ${ }^{22,23}$ In the preparation of catalyst, the initial washed and dried lignin ( $3 \mathrm{~g}$ ) was dissolved in $12 \mathrm{~mL}$ of distilled water in a round bottom flask. The solution was then mixed with $2.4 \mathrm{~mL}$ of formaldehyde and $5 \mathrm{~mL}$ of hydrochloric acid $(37 \%)$. The slurry formed was immersed in an oil bath $\left(90^{\circ} \mathrm{C}\right)$ under stirring for $5 \mathrm{~h}$. After the phenol formaldehyde condensation reaction was completed, the solid was separated by filtration and dried at 105 ${ }^{\circ} \mathrm{C}$ for $4 \mathrm{~h} .{ }^{20}$ The sulfonation reaction was carried out by adding the sample into $10 \mathrm{~mL}$ concentrated sulfuric acid, ${ }^{23}$ and the suspension was stirred at $150^{\circ} \mathrm{C}$ for $2 \mathrm{~h}$. The black solid material was filtered and thoroughly washed repeatedly with hot and cold water until no sulfur-containing were detected in the wash water. The final product was dried at $105{ }^{\circ} \mathrm{C}$ and was evenly crushed with a mortar.

\subsubsection{Catalyst characterization}

The molar amount of $-\mathrm{SO}_{3} \mathrm{H}$ per gram of lignin catalyst (indicated as $\mathrm{M}-\mathrm{SO}_{3} \mathrm{H}$ ) was determined by acid-base titration that was modified from the literature. ${ }^{20}$ In this determination, the aqueous $2 \mathrm{~mol} / \mathrm{L}$ sodium chloride solution $(20 \mathrm{~mL})$ and the lignin catalyst $(0.1 \mathrm{~g})$ were mixed in an Erlenmayer flask and the mixture was sonicated for $1 \mathrm{~h}$ and filtered. The solution was then titrated with the standardized $0.1 \mathrm{~mol} / \mathrm{L}$ sodium hydroxide solution using phenolphthalein as an indicator. The total molar amount of acid groups $-\mathrm{SO}_{3} \mathrm{H},-\mathrm{CO}_{2} \mathrm{H}$, and $-\mathrm{OH}$ (i.e., the sum of $\mathrm{M}-\mathrm{SO}_{3} \mathrm{H}, \mathrm{M}-\mathrm{CO}_{2} \mathrm{H}$, and $\mathrm{M}-\mathrm{OH}$ ) was determined by acid-base 
titration described in the literature. ${ }^{24}$ In this determination, about $0.1 \mathrm{~g}$ of lignin catalyst was added to $40 \mathrm{~mL} 0.1 \mathrm{~mol} / \mathrm{L} \mathrm{NaOH}$ and the solution was then shaken for $4 \mathrm{~h}$ and filtered. The solution was back titrated with the standard $0.1 \mathrm{~mol} / \mathrm{L} \mathrm{HCl}$ solution using a $\mathrm{pH}$ meter and thus, the amount of the $\mathrm{NaOH}$ consumed corresponded to the total amount of acid groups. In the third determination, about $0.1 \mathrm{~g}$ of lignin catalyst was added to $25 \mathrm{~mL}$ of $0.08 \mathrm{~mol} / \mathrm{L}$ $\mathrm{NaHCO}_{3}$ solution and this solution was sonicated for $2 \mathrm{~h}$ and filtered. The solution was then titrated with $0.1 \mathrm{~mol} / \mathrm{L} \mathrm{HCl}$ to $\mathrm{pH} 3.9$ resulting in the total molar amount of acid groups $\mathrm{SO}_{3} \mathrm{H}$ and $-\mathrm{CO}_{2} \mathrm{H}$ (i.e., the sum of $\mathrm{M}-\mathrm{SO}_{3} \mathrm{H}$ and $\mathrm{M}-\mathrm{CO}_{2} \mathrm{H}$ ), which was obtained from the $\mathrm{NaHCO}_{3}$ consumed. Finally, $\mathrm{M}-\mathrm{OH}$ was obtained by subtracting $\Sigma \mathrm{M}-\mathrm{SO}_{3} \mathrm{H}+\mathrm{M}-\mathrm{CO}_{2} \mathrm{H}$ from $\Sigma \mathrm{M}-\mathrm{SO}_{3} \mathrm{H}+\mathrm{M}-\mathrm{CO}_{2} \mathrm{H}+\mathrm{M}-\mathrm{OH}$.

The elemental composition of lignin catalyst was examined using a scanning electron microscope EVO-50 (Carl Zeiss AG, Oberkochen, Germany) equipped with an energy dispersive X-ray spectrometer (Bruker GmbH, Germany) (SEM-EDX). The results were handled with the Bruker Quantax. For the determination, the samples were dried and impacted on $12 \mathrm{~mm}$ carbon tape (Pelco Tabs, Ted Pella, CA, USA) over a sample stub. The samples were analyzed with a magnification of $167 \times$ and X-ray spectra were acquired for a live time of $90 \mathrm{~s}$ over an energy range of $0-10 \mathrm{kV}$ (with a beam current of $30 \mu \mathrm{A}$ and an accelerating voltage of $10 \mathrm{kV}$ ).

FT-IR spectra of lignin catalyst were recorded with a Tensor27 FT-IR spectrometer (Bruker GmbH, Germany). The spectra were taken as an average of 32 scans with a resolution of $4 \mathrm{~cm}^{-1}$ in the wave number between $400 \mathrm{~cm}^{-1}$ and $4000 \mathrm{~cm}^{-1}$. The results were handled with the Bruker Opus version 6.5 software.

\subsubsection{Analysis of fatty and resin acids}

For quantitative analysis of compounds in the commercial fraction of TOFAs (Forchem Oy, Finland), the sample was diluted with acetone $(0.5 \mathrm{mg} / \mathrm{mL})$ and derivatized at $70{ }^{\circ} \mathrm{C}$ for $1 \mathrm{~h}$ for a gas chromatography system equipped with a flame-ionization detector (GC/FID) with a mixture of $\mathrm{N}, \mathrm{O}$-bis(trimethylsilyl)trifluoroacetamide (BSTFA) and trimethylchlorosilane (TMCS) (99:1 v/v). An Agilent 6850 Series GC System (Agilent Technologies, Santa Clara, CA, USA) with an Equity-5 (30 m $\times 0.32 \mathrm{~mm}$ i.d., film thickness $0.25 \mu \mathrm{m})$ column was used. The injector temperature was $290^{\circ} \mathrm{C}$ and the detector temperature was $300{ }^{\circ} \mathrm{C}$. The $\mathrm{GC}$ oven temperature program was $1.5 \mathrm{~min}$ at $100{ }^{\circ} \mathrm{C}$, followed 
by an increase of $6^{\circ} \mathrm{C} / \mathrm{min}$ to $180{ }^{\circ} \mathrm{C}, 10 \mathrm{~min}$ at $180{ }^{\circ} \mathrm{C}$, an increase of $4{ }^{\circ} \mathrm{C} / \mathrm{min}$ to $290{ }^{\circ} \mathrm{C}$, and $20 \mathrm{~min}$ at $290{ }^{\circ} \mathrm{C}$. The relative mass-based response factors used between the GC peak areas derived from the internal standard heneicosanoic acid and those of compounds were equal to 1. Qualitative analysis of the individual components was performed with an Agilent 6890 Series GC System equipped with a 7683 injector and an Agilent 5973 mass selective detector (GC/MSD). In this case, the capillary column used was an HP-5MS (30 $\mathrm{m} \times 0.32$ mm i.d., film thickness $0.25 \mu \mathrm{m}$ ) and the GC oven temperature program was the same as that used in the quantitative analyses.

\subsubsection{Microwave-assisted esterification}

Before esterification the TOFAs were pretreated in an oven at $65^{\circ} \mathrm{C}$ for $2 \mathrm{~h}$. In the esterification experiments about a 1.4-g mixture of TOFAs was added to $0.48 \mathrm{~g}$ of methanol (molar ratio 1:3) in the presence of $5 \mathrm{wt} \%$ a solid lignin catalyst. The reaction was carried out at $100{ }^{\circ} \mathrm{C}$ for $10 \mathrm{~min}$ to $60 \mathrm{~min}$ in a microwave reactor (CEM-Discover, CEM Corporation, Mathews, NC, USA) equipped with a magnetic stirrer and air cooling system. After the reaction the catalyst was filtered off, washed, and dried. The reusability of the lignin catalyst was conducted by the same procedure with the recycled catalyst. For the comparison, the separate sets of reactions under the same conditions were made in the absence of catalyst and also in the presence of $5 \mathrm{wt} \%$ Amberlyst 15 and $p$-toluenesulfonic acid (PTSA) catalysts. The final reaction mixture was carefully separated from heterogeneous catalyst and methanol was separated by evaporation. Finally, the products were washed with water to remove the unreacted fatty acid residues and dissolved PTSA.

\subsubsection{Analysis of methyl esters}

Quantitative analysis of the FAMEs produced was performed by a GC Shimadzu GC-2010 (Chiyoda-ku, Tokyo, Japan) equipped with FID. A capillary column ZBWax (30 m x $0.25 \mathrm{~mm}$ i.d., film thickness $0.25 \mu \mathrm{m}$ ) was used to separate the methyl esters. Hexane and methyl heptadecanoate were used as solvent and internal standard (the relative mass-based response used factors were equal to 1), respectively. The sample of FAMEs (2 $\mathrm{mg} / \mathrm{mL})$ mixed with the internal standard $(1 \mathrm{mg} / \mathrm{mL})$ in hexane was injected into GC/FID. The GC oven temperature program was $2 \mathrm{~min}$ at $100{ }^{\circ} \mathrm{C}, 6^{\circ} \mathrm{C} / \mathrm{min}$ to reach $250{ }^{\circ} \mathrm{C}$, and hold 
for $15 \mathrm{~min}$, creating a total run time of approximately $42 \mathrm{~min}$. The injection port had a temperature of $250{ }^{\circ} \mathrm{C}$ and the temperature of FID was $250{ }^{\circ} \mathrm{C}$, with hydrogen and air flows at $40.0 \mathrm{~mL} / \mathrm{min}$ and $400 \mathrm{~mL} / \mathrm{min}$, respectively. The results were handled with a Shimadzu LabSolutions (GCsolution, Release 2.3.1) chromatograph data system.

\section{Results and discussion}

The density of functional acid groups in the lignin catalyst was determined by different base titrations (Table 1). The density of $-\mathrm{SO}_{3} \mathrm{H}$ groups in the lignin catalyst was observed to be clearly lower than that in the commercial ion exchange resin Amberlyst 15 catalyst. However, the total acidity of the lignin catalyst was about $3.1 \mathrm{mmol} / \mathrm{g}$ and it almost accounted for $73 \%$ of that of Amberlyst 15 . The total acid density of the recycled lignin catalyst was reduced by $15 \%$ compared to that of the fresh catalyst. The FT-IR spectrum of the lignin catalyst (Figure S2) showed the vibration bands at $1030 \mathrm{~cm}^{-1}\left(\mathrm{SO}_{3}\right.$ stretching) and $1149 \mathrm{~cm}^{-1}$ (S-O-S is stretching in $-\mathrm{SO}_{3} \mathrm{H}$ ) indicating the presence of $-\mathrm{SO}_{3} \mathrm{H}$ groups. ${ }^{20}$ The observed vibration bands at $1557 \mathrm{~cm}^{-1}$ and $1698 \mathrm{~cm}^{-1}$ were probably the plane deformation $\mathrm{OH}$ and the $\mathrm{C}=\mathrm{O}$ stretching of $-\mathrm{CO}_{2} \mathrm{H}$ groups, respectively. ${ }^{21}$

Table 1 Density of acid groups in the catalysts (mmol/g)

\begin{tabular}{llll}
\hline Sample & $-\mathrm{SO}_{3} \mathrm{H}$ & $-\mathrm{CO}_{2} \mathrm{H}$ & $-\mathrm{OH}$ \\
\hline Lignin catalyst & $1.4 \pm 0.2$ & $0.9 \pm 0.2$ & $0.8 \pm 0.1$ \\
Recycled lignin catalyst & $1.2 \pm 0.2$ & $0.7 \pm 0.1$ & $0.7 \pm 0.1$ \\
Amberlyst 15 & $4.2 \pm 0.1$ & - & - \\
\hline
\end{tabular}

The elemental analysis of lignin catalyst showed the presence of sulfur (from $-\mathrm{SO}_{3} \mathrm{H}$ ) along carbon and oxygen (Table 2). As increase in the carbon content (due to the presence of fatty acid impurities), sulfur content in the recycled catalyst was reduced by $25 \%$ compared to that of the fresh catalyst. There was no difference observed between the particle size of the initial lignin catalyst and recycled catalyst shown in Figure 1. 

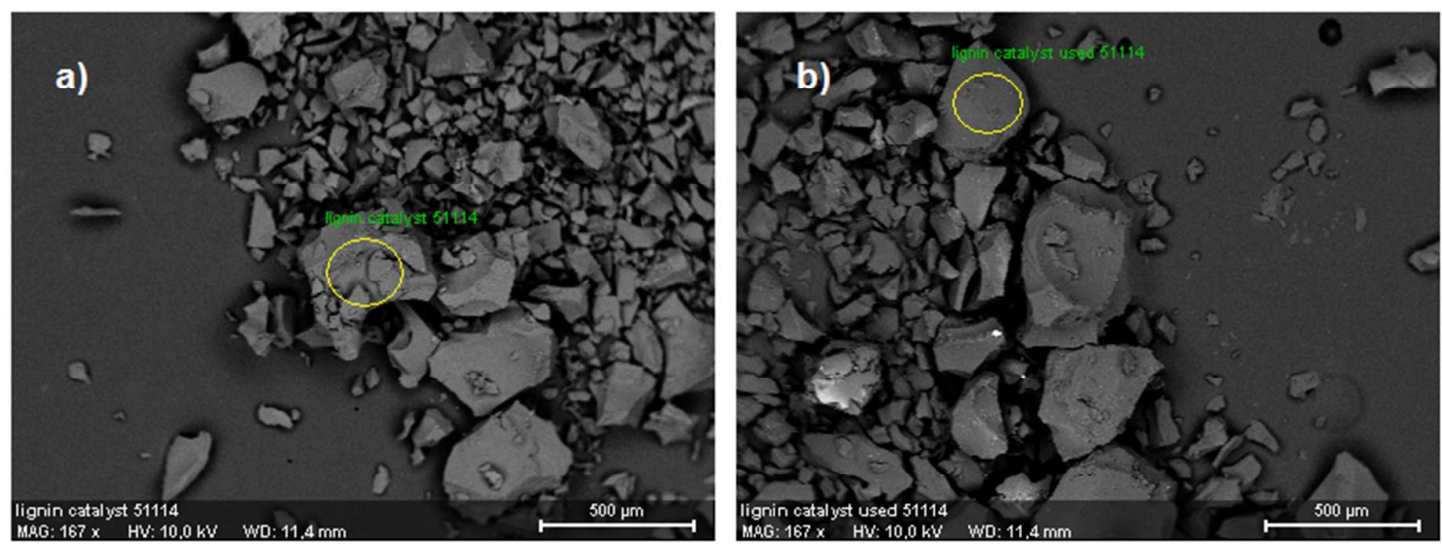

Figure 1 SEM micrographs of a) lignin catalyst and b) recycled lignin catalyst.

Table 2 Elemental analysis of the lignin catalysts (wt\%)

\begin{tabular}{lccc}
\hline Sample & $\mathrm{C}$ & $\mathrm{O}$ & $\mathrm{S}$ \\
\hline Initial & $57.7 \pm 4.8$ & $38.6 \pm 3.2$ & $3.7 \pm 0.4$ \\
Recycled & $66.4 \pm 5.3$ & $30.8 \pm 4.0$ & $2.8 \pm 0.1$ \\
\hline
\end{tabular}

The composition of various fatty acids and resin acids in the fraction of TOFAs is presented in Figure 2. The main fatty acid components were linoleic $\left(\mathrm{C}_{18: 2}\right)$, oleic $\left(\mathrm{C}_{18: 1}\right)$, and linolenic $\left(\mathrm{C}_{18: 3}\right)$ acids that corresponded to about $49 \%, 27 \%, 9 \%$ of the total fatty acids, respectively.

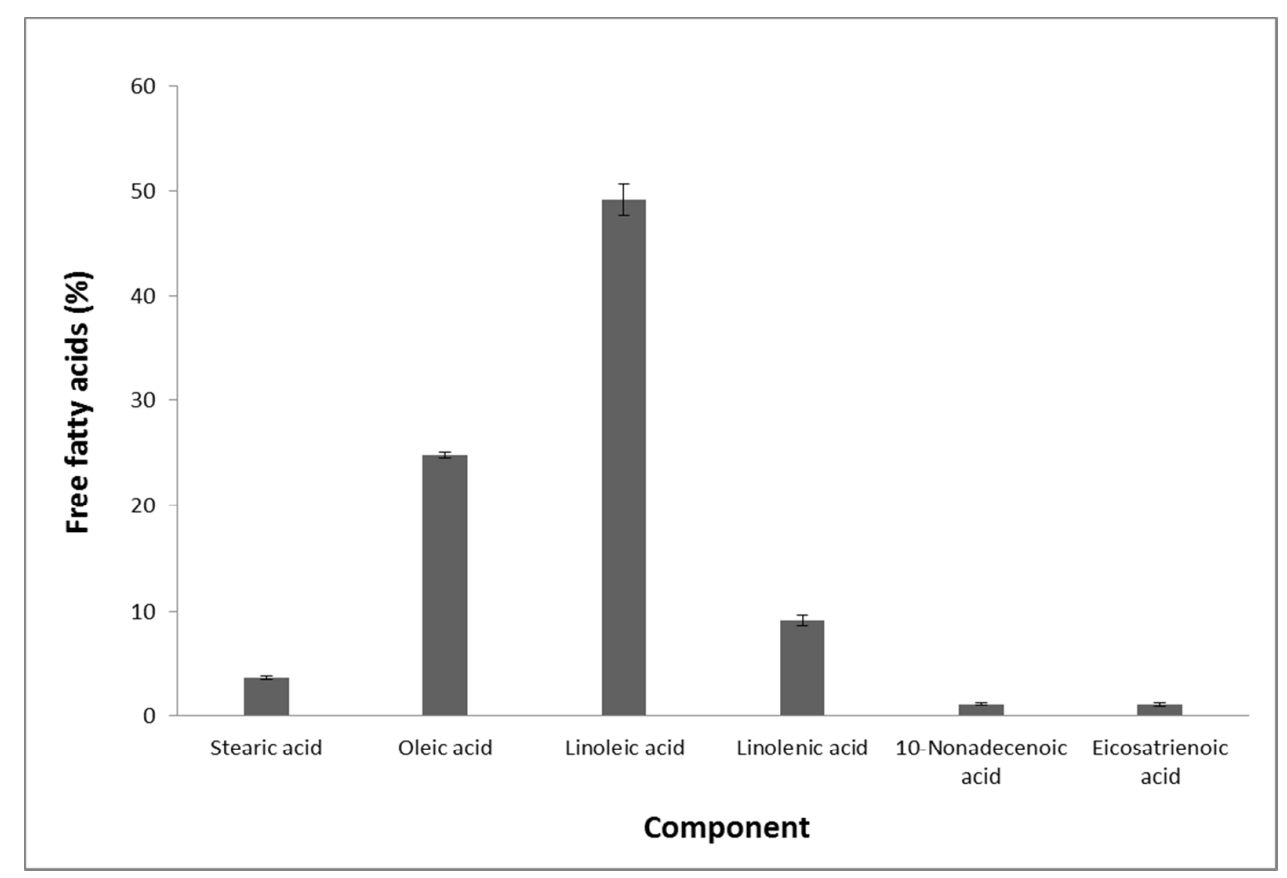

Figure 2 Weight percentages of fatty acids in the TOFAs product containing $92.4 \%$ fatty acids, $3.2 \%$ resin acids, and $4.4 \%$ miscellaneous compounds. 
The acid properties of the lignin catalyst material were tested for the microwave-assisted esterification of TOFAs with methanol. The reactions were carried out at different time intervals under the same conditions. Additionally, the activity and reusability of the lignin catalyst were compared under the same conditions to those of different catalytic (with Amberlyst 15 and PTSA) and non-catalytic reactions. The microwave esterification at a low methanol to fatty acids ratio showed a good yield for the catalytic reactions compared to that of the non-catalytic one. The lignin catalyst resulted almost in a FAMEs yield of $88 \%$ which was slightly higher than that ( $80 \%$ ) obtained with the Amberlyst 15 catalyst (Figure 3$)$. The maximum yield of $93 \%$ was achieved with the homogeneous PTSA catalyst and the lowest one $(20 \%)$ by the non-catalytic reaction for $60 \mathrm{~min}$. It should be pointed out that with the lignin catalyst, a FAMEs yield of about $67 \%$ and $76 \%$ could be obtained within a short reaction time of $10 \mathrm{~min}$ and $30 \mathrm{~min}$, respectively.

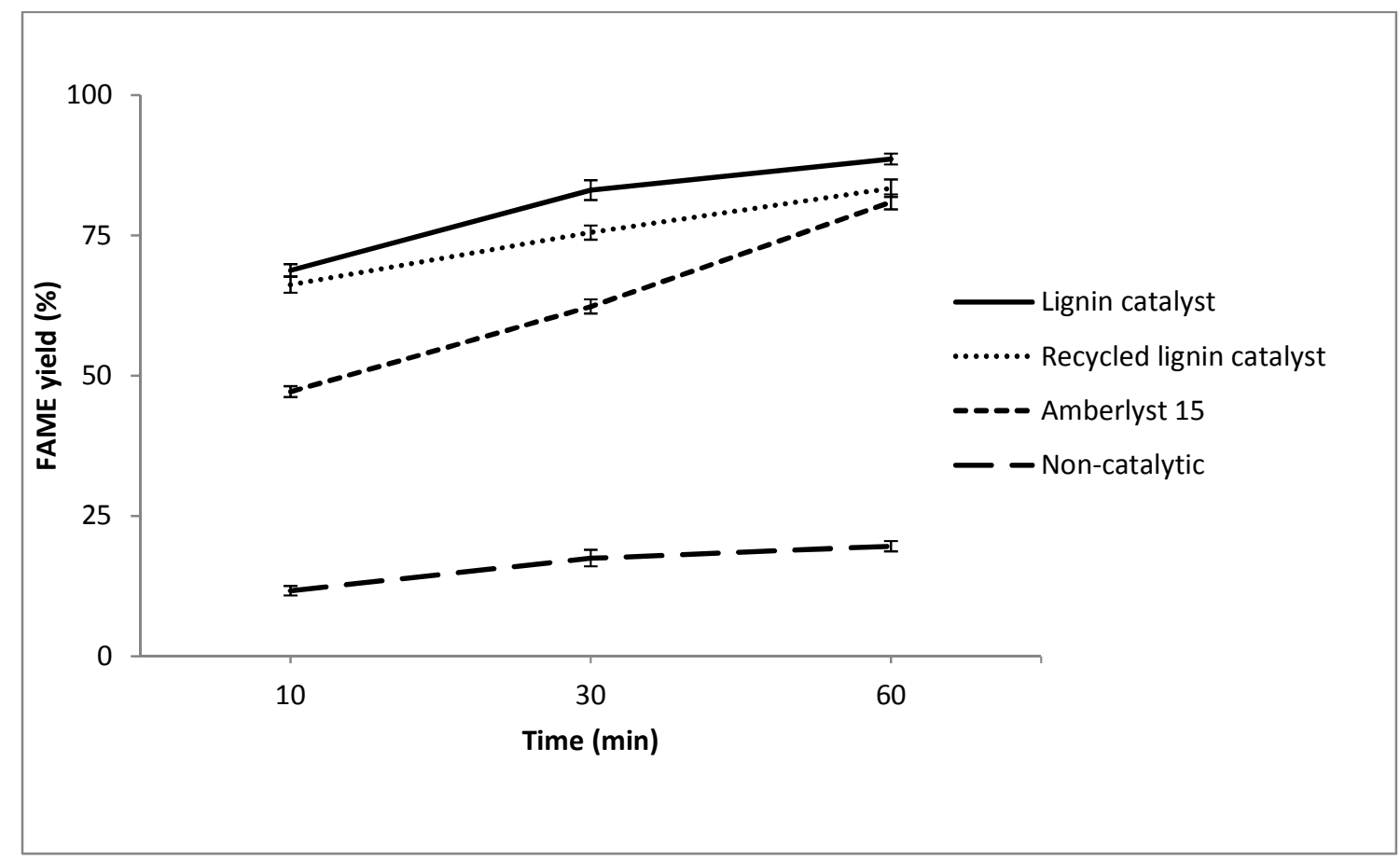

Figure 3 Esterification yields of fatty acids with methanol at various reaction times, at 100 ${ }^{\circ} \mathrm{C}$, and with heterogeneous catalytic and non-catalytic reaction.

The esterification yields of the individual fatty acids varied. The TOFAs studied mainly consisted of unsaturated fatty acids; approximately about $83 \%$ of the total compounds. The oleic acid (a monoenoic acid) and linoleic acid (a dienoic acid) showed a higher FAME yield of approximately $85 \%$ compared to that of linolenic acid (a trienoic acid) corresponding to a FAME yield of approximately $60 \%$ with heterogeneous catalyst for $60 \mathrm{~min}$ (Figure 4). The 
crude FAMEs produced using lignin-based acid catalyst might contain unreacted fatty acids and resin acids along with some minimal amount of sulfur (sulfonyl acid groups) from catalyst leaching. The reusability of the lignin acid catalyst was also tested; the results suggested no significant decrease in the activity. The proper activation of lignin catalyst may further increase the reusability of it for several times. One interesting further aspect in this overall approach is that even crude methanol may also be separated from the relief gases of alkaline pulping. ${ }^{9}$

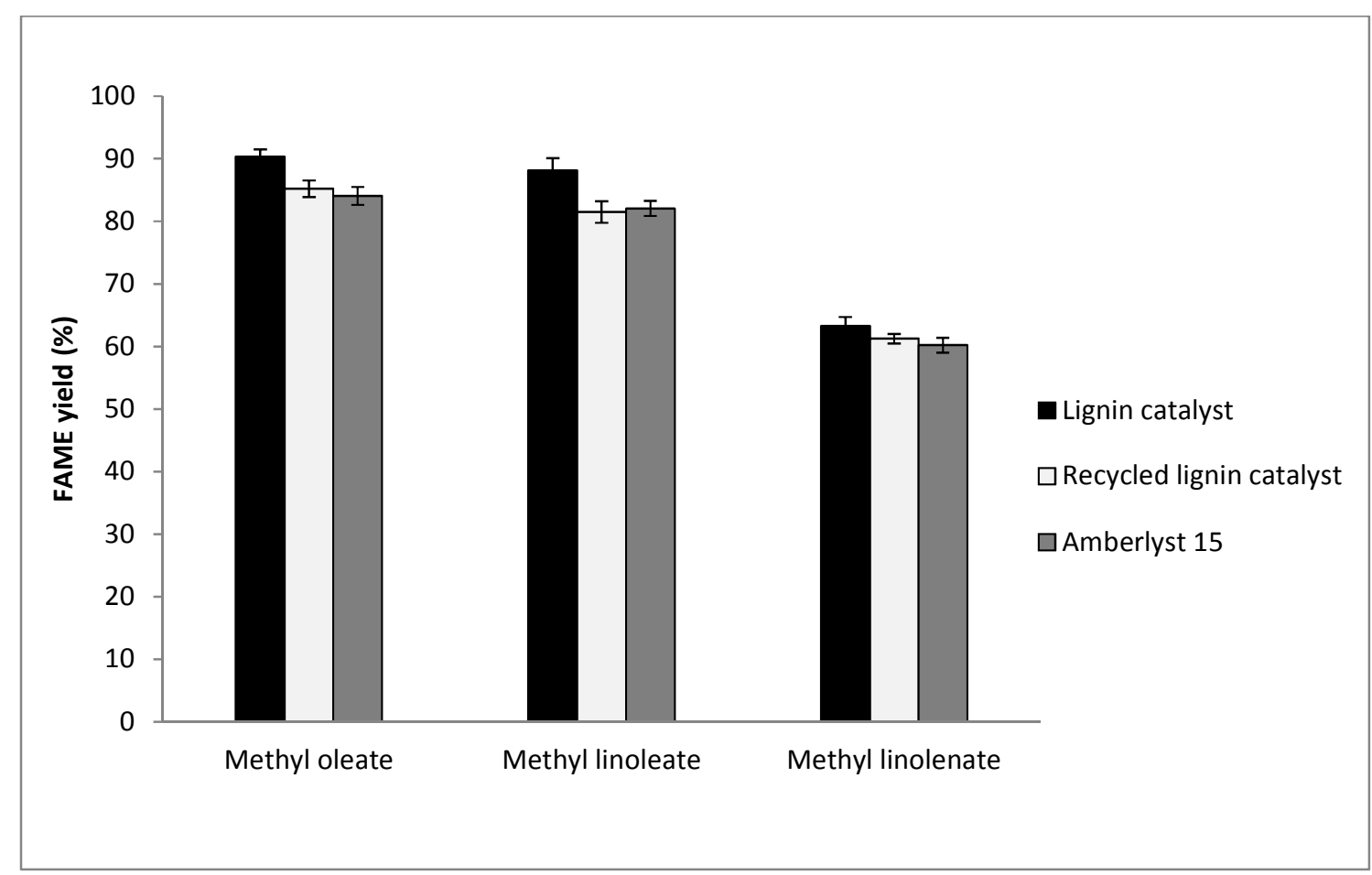

Figure 4 Esterification yields of oleic, linoleic, and linolenic acids with methanol at various reaction times, at $100{ }^{\circ} \mathrm{C}$, and with heterogeneous catalysts.

\section{Conclusions}

A substantial amount of organic material, especially degraded lignin and carbohydrate-derived aliphatic carboxylic acids occurs in the black liquor from alkaline pulping. In this study, a heterogeneous catalyst containing $-\mathrm{SO}_{3} \mathrm{H},-\mathrm{CO}_{2} \mathrm{H}$, and $-\mathrm{OH}$ groups was produced from the acid-precipitated alkaline lignin by the phenol formaldehyde condensation and sulfonation reaction. This lignin catalyst exhibited high activities in the acid-catalyzed esterfication of tall oil fatty acids with methanol. This is an interesting approach in the utilization of both these by-products of alkali pulping into valuable products. 
Compared to other catalysts (Amberlyst 15 and PTSA) tested the lignin-based catalyst showed a good activity and it can also be easily recycled.

\section{ASSOCIATED CONTENT}

\section{Supporting Information}

Additional information is available free of charge on the ACS Publications website at DOI:

Production principle of tall oil fatty acid methyl esters (Figure S1) and FTIR spectra of lignin catalyst (Figure S2).

\section{Acknowledgement}

The authors gratefully acknowledge the financial support of the Foundation for Research of Natural Resources in Finland (Suomen Luonnonvarain Tutkimussäätiö).

\section{References}

1. Saka, S.; Kusdiana, D., Biodiesel fuel from rapeseed oil as prepared in supercritical methanol. Fuel 2001, 80 (2), 225-231.

2. Vijayaraghavan, K.; Hemanathan, K., Biodiesel production from freshwater algae. Energy Fuels 2009, 23 (11), 5448-5453.

3. Demirbas, A., Importance of biodiesel as transportation fuel. Energy Policy 2007, 35 (9), 4661-4670.

4. Christopher, L. P.; Kumar, H.; Zambare, V. P., Enzymatic biodiesel: challenges and opportunities. Appl. Energy 2014, 119, 497-520.

5. Demirbas, A., Production of biodiesel from tall oil. Energy Source Part A 2008, 30 (20), 1896-1902.

6. Behzadi, S.; Farid, M., Review: examining the use of different feedstock for the production of biodiesel. Asia Pac. J. Chem. Eng. 2007, 2 (5), 480-486.

7. Lokman, I. M.; Rashid, U.; Zainal, Z.; Yunus, R.; Taufiq-Yap, Y. H., Microwaveassisted biodiesel production by esterification of palm fatty acid distillate. J. Oleo Sci. 2014, 63 (9), 849-855. 
8. Miao, X.; Wu, Q., Biodiesel production from heterotrophic microalgal oil. Bioresour. Technol. 2006, 97 (6), 841-846.

9. Alén, R., Basic chemistry of wood delignification. In Forest Products Chemistry, P. Stenius (Ed.), Fapet Oy, Helsinki, Finland, 2000, pp. 59-104.

10. Coll, R.; Udas, S.; Jacoby, W. A., Conversion of the rosin acid fraction of crude tall oil into fuels and chemicals. Energy Fuels 2001, 15 (5), 1166-1172.

11. Lappi, H.; Alén, R., Pyrolysis of tall oil-derived fatty and resin acid mixtures. Int. Sch. Res. Notices 2012, 2012.

12. Lappi, H. E.; Alén, R., Pyrolysis of crude tall oil-derived products. BioResources 2011, 6 (4), 5121-5138.

13. Altıparmak, D.; Keskin, A.; Koca, A.; Gürü, M., Alternative fuel properties of tall oil fatty acid methyl ester-diesel fuel blends. Bioresour. Technol. 2007, 98 (2), 241-246.

14. Keskin, A.; Gürü, M.; Altıparmak, D., Biodiesel production from tall oil with synthesized Mn and Ni based additives: Effects of the additives on fuel consumption and emissions. Fuel 2007, 86 (7-8), 1139-1143.

15. Toda, M.; Takagaki, A.; Okamura, M.; Kondo, J. N.; Hayashi, S.; Domen, K.; Hara, M., Green chemistry: Biodiesel made with sugar catalyst. Nature 2005, 438, 178-178.

16. Srilatha, K.; Kumar, C. R.; Devi, B. P.; Prasad, R.; Prasad, P. S.; Lingaiah, N., Efficient solid acid catalysts for esterification of free fatty acids with methanol for the production of biodiesel. Catal. Sci. Technol. 2011, 1 (4), 662-668.

17. Zong, M.-H.; Duan, Z.-Q.; Lou, W.-Y.; Smith, T. J.; Wu, H., Preparation of a sugar catalyst and its use for highly efficient production of biodiesel. Green Chem. 2007, 9 (5), 434-437.

18. Cheng, J.-K.; Chao, C.-C.; Ward, J. D.; Chien, I. L., Design and control of a biodiesel production process using sugar catalyst for oil feedstock with different free fatty acid concentrations. J. Taiwan Inst. Chem. Eng. 2014, 45 (1), 76-84.

19. Lokman, I. M.; Rashid, U.; Yunus, R.; Taufiq-Yap, Y. H., Carbohydrate-derived Solid Acid Catalysts for Biodiesel Production from Low-Cost Feedstocks: A Review. Cat. Rev.-Sci. Eng. 2014, 56 (2), 187-219.

20. Zhang, X.; Zhang, Z.; Wang, F.; Wang, Y.; Song, Q.; Xu, J., Lignosulfonate-based heterogeneous sulfonic acid catalyst for hydrolyzing glycosidic bonds of polysaccharides. J. Mol. Catal. A: Chem. 2013, 377, 102-107. 
21. Liang, F.; Song, Y.; Huang, C.; Zhang, J.; Chen, B., Preparation and performance evaluation of a lignin-based solid acid from acid hydrolysis lignin. Catal. Commun. 2013, 40, 93-97.

22. Alén, R.; Patja, P.; Sjöström, E., Carbon dioxide precipitation of lignin from pine kraft black liquor. TAPPI 1979, 62 (11), 108-110.

23. Kumar, H.; Alén, R., Partial recovery of aliphatic carboxylic acids and sodium hydroxide from hardwood black liquor by electrodialysis. Ind. Eng. Chem. Res. 2014, 53 (22), 9464-9470.

24. Lee, D., Preparation of a sulfonated carbonaceous material from lignosulfonate and its usefulness as an esterification catalyst. Molecules 2013, 18 (7), 8168-8180. 